\title{
Corpos, cadeiras, colares: Charlotte Perriand e Lina Bo Bardi*
}

\author{
Silvana Rubino**
}

\begin{abstract}
Resumo
O artigo investiga, a partir de duas fotografias, os pontos de encontro entre as trajetórias de duas profissionais ligadas à produção do espaço: a arquiteta italiana Lina Bo Bardi, que atuou no Brasil, e a designer francesa Charlotte Perriand. Tomando as imagens como mote, comparamos a atuação dessas duas profissionais de renome, os momentos de exclusão, desclassificacão e também de sucesso de suas carreiras. Como Lina e Charlotte tiveram trajetórias longas e diversificadas, flagramos apenas dois momentos, o da produção de cadeiras emblemáticas que elas exibiram usando, ainda que de modo pretensamente anônimo, seus corpos como medida ergonométrica.
\end{abstract}

Palauras-chave: Lina Bo Bardi, Charlotte Perriand, Modernismo, Espaço Doméstico, Design.

\footnotetext{
" Recebido para publicação em julho de 2009, aceito em março de 2010.

** Professora do Departamento de História do IFCH/Unicamp. srubino@uol.com.br
}

cadernos pagu (34), janeiro-junho de 2010:331-362. 
Corpos, cadeiras, colares

Bodies, Chairs, Necklaces: Lina Bo Bardi and Charlotte Perriand

\begin{abstract}
The article explores the crossroads of the trajectories of two professional women linked to the production of space: the Italian architect Lina Bo Bardi, who worked in Brazil, and the French designer Charlotte Perriand. The article begins by comparing two photographs and then investigates the performance of these two well-known professionals, their moments of exclusion, disqualification as well as success throughout their careers. As they both had long and diversified careers, we capture two moments when they produced the emblematic chairs, that they exhibited using their own bodies, albeit in a quite anonymous way, as an ergonometric measure.
\end{abstract}

Key Words: Lina Bo Bardi, Charlotte Perriand, Modernism, Domestic Space, Design. 
A inquietação ocasionada pela semelhança de postura corporal e da relação entre corpo e objeto - no caso, duas cadeiras - em duas fotografias provocou uma reflexão que deu início a uma nova pesquisa $e$ a este texto. Posadas, estudadas $e$ controladas, as imagens mostram duas mulheres sentadas em cadeiras por elas desenhadas. Nas respectivas fotografias, estas mulheres vinculadas ao modernismo arquitetônico usam seus corpos como medida ergonométrica para suas obras. Embora ocultem os rostos, como se quisessem se tornar anônimas, sabemos de quem se trata e em diversas ocasiões as fotografias foram utilizadas como assinaturas, como imagem-símbolo que remetia à autoria. Essas semelhanças aparentes começam a se dissipar se notamos a indumentária das mulheres retratadas, certamente um primeiro sinal da distância que separa 1929, com a jovem Charlotte Perriand de vestido e sapatos femininos posando para mostrar sua cadeira em uma exposição, de 1951 com a já reconhecida arquiteta Lina Bo Bardi, de calça comprida e sapatos fechados, mostrando, em diversas poses a versatilidade de sua cadeira. De qualquer modo, uma relação corporal que remete a repouso e feminilidade, além de um lembrete de autoria que assina as fotos e coloca duas cadeiras como obras únicas: pontos de similitude que nos convidam a ensaiar uma aproximação a qual, trazendo momentos das trajetórias das duas artistas, aliadas à cultura material e visual, nos permite especular a respeito de relações entre gênero e produção cultural.

Para além das semelhanças encontradas nos dois retratos, a proposta de analisar esses dois casos de trajetórias bem-sucedidas, com carreira, obra e visibilidade, pretende argumentar que, mais do que as mulheres que ficaram à margem, aquelas que freqüentaram o centro de seus respectivos campos podem dizer algo de novo a respeito da silenciosa divisão de trabalho por gênero no interior da prática arquitetônica do século $\mathrm{XX}$, assim como revelar um modernismo no feminino. Afinal, quando nos perguntamos sobre a participação feminina nos grupos de arquitetos modernos, seus nomes se impõem (ao lado de outros 
Corpos, cadeiras, colares

como Eileen Gray, Ray Eames, Alison Smithson) como se suas meras presenças e o sucesso que obtiveram não pudessem indicar $e$ indiciar formas sutis de sujeição e auto-sujeição cujas tensões aparecem inclusive em suas obras e no modo como elas foram exibidas - por isso a centralidade das fotos. Afinal, a história da arquitetura, comumente surda a indagações de gênero, poderia se perguntar se há algo a mais no conhecido aforismo de Walter Gropius - que se tornou uma auto-representação do campo para quem, da colher à cidade, tudo poderia ser tarefa do arquiteto. Nesse espectro talvez algumas escalas tenham ficado a cargo de arquitetas, no feminino, ou de mulheres cuja formação complementava as realizações dos arquitetos do assim chamado movimento moderno. A fala do fundador da Bauhaus, sobre escalas que parecem equivalentes, oculta uma hierarquia de gêneros, nos dois sentidos, que era praticada nos ateliês da escola desde sua fundação em Weimar em 1919.

Lina Bo Bardi e Charlotte Perriand lograram construir um nome reconhecido, mas por isso mesmo é preciso desmistificar o sucesso dessas heroínas solitárias e ver como de certo modo trajetórias e obras se articulam a saberes e práticas que tiveram lugar no século XIX e começo do XX. O registro da excepcionalidade só faz sentido se a situarmos numa exceção mais ampla do que suas qualidades singulares: em um conjunto de circunstâncias que se combinaram de modo pouco comum. Nessas circunstâncias, é imperativo levarmos a sério alguns momentos de demarcação de fronteiras de gênero nas trajetórias de Bardi e Perriand. Quando Lina, ao se formar em arquitetura recebeu de Marcello Piacentini o veredicto de que se casaria, bella ragazza, para não exercer a profissão, temos um momento simétrico à recepção que Le Corbusier deu à jovem Charlotte que batia à porta de seu ateliê em busca de trabalho: "aqui não bordamos almofadas". Nesses rituais de não investimento o mundo doméstico aparece como o destino feminino ao mesmo tempo em que estabelece uma hierarquia: o lugar para onde elas deveriam retornar não era dos mais desejados pelo mundo dessas 
profissões masculinas. Ou seria? Segundo Beatriz Colomina nada distinguiu mais a arquitetura do século XX do que o papel crucial da casa privada, com idéias importantes de Adolf Loos, Le Corbusier e outros, sendo elaboradas por meio dos projetos de residência - casas que os tornaram conhecidos, tenham ou não sido construídas, especialmente aquelas que foram projetadas para mostras, publicações e concursos.

Pontos de aproximação à parte, é preciso assinalar que a tarefa de rever alguns cânones dessa história, como o papel crucial dos grandes nomes, não diz respeito apenas à presença feminina. O papel dos ateliês, cooperativas, grupos, escolas, agremiações etc. é crucial. Charlotte Perriand não foi a única figura nublada do ateliê de Le Corbusier, e recuperar seu papel é trazer à luz nomes como Pierre Jeanneret e Alfred Roth, para citar apenas alguns. Lina Bo Bardi, por sua vez, pode ter em sua condição feminina apenas uma parte da explicação de seus vôos solo - afinal, era uma italiana trabalhando em São Paulo no período pós-1956, momento em que a arquitetura moderna brasileira concentrava-se no Rio de Janeiro e ainda elaborava em diversos tons um discurso de brasilidade. Ainda assim, tanto no Museu de Arte de São Paulo (MASP) como no Museu de Arte Moderna da Bahia (MAMB), trabalhava em grupo, $e$ as nuances de sua parceria com Pietro Maria Bardi ainda não foram suficientemente avaliadas.

Instaurar gênero como um dos condicionantes da ação dessas artistas é pensar relacionalmente, confrontando duas ordens de hierarquias: gênero e gênero artístico. E colocar essas personagens em relações onde essas demarcações podem aparecer. Não se trata apenas da glamurosa Charlotte num ateliê masculino ou de Pietro Maria Bardi definindo o conhecido museu projetado por sua esposa como "um sonho de mulher". Seria preciso lembrar como a literatura tratou Sonia Delaunay e sua presumida relação maternal $e$ instintiva com as cores (recordando que ela evidenciou sua pesquisa numa colcha para o filho recémnascido) se comparada à abordagem intelectual e lógica de 
Corpos, cadeiras, colares

Robert ${ }^{1}$; a relação de Anni Albers (1889-1994) com a tapeçaria enquanto Joseph (1888-1976) dedicava-se à teoria das cores ${ }^{2}$; a bem formada e vanguardista Ray (Kaiser) Eames (1912-1988) passando a braço direito de Charles (1907-1978). ${ }^{3}$ Os exemplos são inúmeros $e$ interessam especialmente por remeterem a divisões culturalmente constituídas que, repetidas e reiteradas na longa duração, ganharam quase um caráter de dualidade universal. ${ }^{4}$

1 A ucraniana Sonia Terk chegou em Paris em 1905 aos vinte anos e conheceu Robert Delaunay em 1908, iniciando uma intensa parceria pessoal e artística. A partir de 1910 o trabalho de cada um deles começou a tender à abstração, que Robert denominava "desconstrução" enquanto Sonia a experimentava em superfícies têxteis. Sonia tornou-se particularmente conhecida pelas roupas que desenhou e quando a obra de Robert tornou-se mais consistente em relação aos debates estéticos dos anos 1910, a obra de Sonia voltou-se para colagens, pastéis, tecidos e objetos domésticos. A respeito do trabalho do casal Delaunay, ver Chadwick (1993).

2 O casal Albers se conheceu em 1922 na Bauhaus. Ele foi um dos mais influentes professores de pintura da escola, autor de uma teoria das cores, enquanto ela, cujo nome de solteira era Annelise Fleischmann, dedicou-se à tecelagem e a escritos sobre design. Em 1933 - Anni era judia - o casal migrou para os Estados Unidos, de onde empreenderam uma série de viagens pela América Latina.

3 Charles Eames abandonou o curso de arquitetura no segundo ano, trabalhando como fotógrafo e também com diversas modalidades de artesanato como cerâmica e impressão. Sua adesão ao design moderno deu-se em grande medida por sua proximidade com o designer Eliel Saarinen e sua esposa Loja, e posteriormente seu filho Eero. Em 1941 casou-se com Ray Kaiser, pintora e escultora formada em Nova York e militante do grupo AAA (American Abstracts Artists). Pat Kirkham observa o quanto a comum dualidade que em parcerias artísticas vincula a mulher ao universo do artesanato e o homem ao da abstração era inversa no momento em que o casal iniciou sua parceria amorosa e artística. (Kirkham, 1998:21)

4 A própria pedagogia da Bauhaus trabalhava nessa dualidade. A herança histórica européia, vista como opressora era vista como "feminina" e "maternal", enquanto que a admirada indústria norte-americana era percebida como masculina. Herbert Bayer(1900-1985) trabalhava com esses opostos: os gostos da cultura popular e de massa, irracionais e femininos deveriam ser disciplinados pela tipografia e pelo desenho, equivalentes ao pai racional e regulador da teoria 
Silvana Rubino

Contudo, para limitar a circunscrição desse texto, trataremos dos momentos em que Lina Bo Bardi e Charlotte Perriand desenharam suas cadeiras $e$ as exibiram publicamente com seus corpos. Não se trata de construir a trajetória das duas artistas e sim de flagrar dois momentos de suas carreiras, situados nos dois pósguerras do século $\mathrm{XX}$, nos quais gênero e produção estiveram especialmente emaranhados.

\section{CHARLOTTE PERRIAND}

Nascida em 1903, em Paris, filha de um alfaiate e uma modista, Charlotte Perriand cresceu nas redondezas do Marché Saint-Honoré, onde seus pais residiam e trabalhavam, observando o ambiente da alta-costura da perspectiva do pequeno artesão (McLeod, 2003:11). Se na Paris posterior às intervenções de Haussmann manteve-se ainda o espaço das manufaturas, o crescente consumo dos bens de decoração e vestimenta reservou à mulher, desde os escritos dos irmãos Goncourt, um papel de guardiã da graça, estilo e embelezamento. ${ }^{5}$ Os pais e, em especial a mãe de Charlotte, estavam no pólo do pequeno produtor dessa

freudiana. "Esses limites são ecoados na dicotomia estabelecida por Bayer entre a cultura popular e o design 'funcional', entre a história (regressiva) o futuro (progressista) e entre o estilo (feminino) e sua rejeição (masculina)" (Mills, 2009:50).

5 No final do século XIX, escritor e colecionador Octave Uzanne denunciava a simplicidade das femmes nouvelles como prejudicial para as artes decorativas francesas, que careciam da forma e do adorno femininos. Esse pioneiro em uma escrita que reintegrava artes e crafts preconizava uma aliança entre a graça feminina, o espaço interior e o refinamento artesanal, desde o século XVIII. Seu trabalho La femme à Paris, nos contemporaines, de 1894 dizia que essa sobriedade minava um tipo de mulher parisiense orgânica, decorativa, e discutiu as implicações dessa nova postura às ordens urbana e doméstica. Ele celebrava a habilidade feminina de adornar seu próprio corpo e os espaços interiores aos quais ela naturalmente pertencia, mesclando mulheres decorativas $e$ decoradoras, cujo modelo era a mulher aristocrática artesã, e delegando às esposas burguesas decorarem não apenas as paredes de suas casas, mas também cultivar luxo e artisticidade em suas "roupas de baixo". Ver Silverman (1992:71). 
Corpos, cadeiras, colares

manufatura de bens de luxo, vivendo a transição entre a profusão dos pequenos ateliês e oficinas no centro de Paris nas últimas décadas do século XIX $e$ a ascensão dos grands magasins de nouveautés que arrancaram as mercadorias dos quartiers parisienses jogando-as em espaços que eram também de entretenimento (Clark, 2004:97-101). A filha, seguindo de modo mais estudado no ramo de atividades dos pais, completou tal transição. Em 1920, com dezessete anos, ela ingressou como bolsista no programa de quatro anos da Ecole de l'Union Centrale des Arts Decoratifs, uma escola feminina e feminista ${ }^{6}$ embora muitas das moças tivessem origem nas elites parisienses $e$ a expectativa de um bom casamento. Quando da passagem de Charlotte pela escola, sua direção estava a cargo de mulheres, exceto pelo diretor artístico, Henri Rapin (1873-1939). Mas essa aparente peculiaridade tinha sua origem nas reformulações que a instituição sofreu por volta de 1890 , dentre as quais ecoava a visão desenvolvida em círculos oficiais, de que haveria um papel à mulher na regeneração das artes aplicadas nacionais, $e$ a partir de então a escola envolveu-se em campanhas para a liderança das mulheres na produção e consumo de um artesanato de luxo. Nesse momento, mulheres como Eileen Grey, Sonia Delaunay, Hélène Henry, dentre outras, ganhavam proeminência crescente no panorama da arte decorativa francesa (Costa Meyer, 2003:22).

Uma vez formada, Charlotte recebeu de Rapin o conselho de que buscasse a todo custo expor - afinal, ninguém a conhecia. $\mathrm{O}$ aconselhamento profissional nesse momento assinala o perfil de que não havia freqüentado o curso por diletantismo, mas em

6 A Union Centrale des Arts Decoratifs foi fundada em 1864 como União Central das Belas Artes aplicadas à Indústria. Ficava na Place Royale (hoje Place des Vosges), bem no bairro de artesãos que era o Marais. Seus membros incluíam manufatureiros de papel de parede, tapetes, pianos, ourives etc. A mudança de nome veio com outras alterações em 1890. O termo "indústria" foi suprimido e os objetivos transformados: por volta de 1889, a idéia de vulgarizar o senso de beleza e democratizar a arte foi substituída por uma busca de purificação da beleza e aristocratização do artesanato. Ver Deborah Silverman (1992:111). 
Silvana Rubino

busca de uma qualificação para o trabalho, o que a distinguia de algumas amigas como Dora Maar e Marianne Clouzot, filha do crítico de arte e diretor de museu Henri Clouzot. Charlotte buscou uma segunda formação nos ateliês de pintura de Bernard Boulet de Montvel e posteriormente de André Lohte. Na Paris posterior à Primeira Guerra, as grandes lojas de departamento francesas instituíram seus próprios estúdios de design, e ela frequentou as aulas de Maurice Dufrene $e^{7}$ nas Galeries Lafayette e de Paul Follot ${ }^{8}$ no Bon Marché, que ofereciam atividades mais práticas do que as da escola, que era quase um ateliê familiar. Um dos fundadores da Société des Artistes Décorateurs, Dufrene havia trabalhado com nomes importantes como Victor Horta e Henry van der Velde, e foi com ele que Charlotte desenhou cortinas para um quarto exibido no Salão de Artes Decorativas de 1926, decoração produzida por La Maitrise, do ateliê Lafayette, peça a partir de então exibida diversas vezes nas vitrines da loja (Costa Meyer, 2003:23).

Dufrene e Follot trabalhavam para grandes lojas, o que os colocava diante da questão da produção em massa e do mercado, e o que se esperava deles era que fizessem cenários para a classe média, em forma e preço, mas eles mantinham o foco no cliente abastado - Dufrene afirmando que a partir do rico se poderia atingir a burguesia e depois o povo, enquanto Follot, muito mais resistente às mudanças, opunha arte serial à própria idéia de arte, antagonizando qualidade e quantidade, como uma banda de jazz com setenta negros em oposição a um quarteto - este último, sem dúvida, sua opção. Em 1925, Maurice Dufrène coordenou uma "rua das lojas", para a exposição internacional das artes decorativas $e$ industriais modernas, projetada, entre outros por

7 Maurice Dufrene (1876-1955) era presidente do Salon des Artistes Décorateurs e diretor artístico da Maïtrise das Galeries Lafayette.

8 Paul Follot era diretor artístico do estúdio Pomme, o ateliê de arte do Bon Marché. 
Corpos, cadeiras, colares

Gabriel Guévrékian ${ }^{9}$, René Herbst ${ }^{10}$ e Francis Jourdan sobre a ponte Alexander III. E Charlotte apresentou Le Neuf Muses, um painel art déco para um salão de música.

Em 1926, a jovem designer apresentou pela primeira vez um ambiente completo no Salão Anual da Societé des Artistes Decorateurs de Paris. Financiada por seus pais, a composição intitulada Coin de Salon, foi recebida como juvenil e criticada por mesclar madeira e vidro. Costa Meyer nota que o trabalho ficava distante daqueles produzidos pelos professores de Charlotte, $e$ buscava aproximar-se dos trabalhos mais vanguardistas apresentados na mesma ocasião, como um quarto que Georges Djo-Bourgeois ${ }^{11}$ fez para uma villa modernista projetada pelo arquiteto Robert Mallet Stevens na Cote d`Azur. O conjunto Coin de Salon foi adquirido por um comerciante inglês de tecidos, Percy Schlonfield, para mobiliar sua garçonière. ${ }^{12}$ Scholenfield, vinte anos mais velho do que Charlotte e amigo de sua família, foi o financiador de um conjunto de luminárias (que ela possivelmente vendeu para a estilista Jeanne Lanvin) (Ruegg, 2004:10) e um armário para prataria finalizado em 1926; também ofereceu cursos de arquitetura, matemática, inglês e de condução de automóvel. Em dezembro do mesmo ano eles se casaram, para surpresa de todos e contra a vontade paterna, devido à religião

\footnotetext{
9 Arquiteto turco que se formou em Viena, em 1919, e mudou-se para Paris, onde trabalhou, entre outros, com Robert Mallet-Stevens, André Luçart e Le Corbusier. A convite deste último, passou a atuar fortemente nos Congressos Internacionais da Arquitetura Moderna (CIAMs).

${ }^{10}$ Arquiteto parisiense nascido em 1891 estudou em Londres e em Frankfurt. Estabeleceu-se em Paris onde atuou como arquiteto de interiores. Foi um dos fundadores da Union des Artistes Modernes.

${ }^{11}$ Georges Djo-Bourgeois (1898-1937) nasceu em Bezons e formou-se em arquitetura em 1922. Integrou a equipe de criadores do Studium Louvre, ligado ao Grands Magazins du Louvre.

${ }^{12}$ A poltrona do conjunto foi exposta na exposição anual de arte aplicada do museu Galliera, dirigido por Henri Clouzot, no inverno de 1926-7.
} 
protestante, à nacionalidade $e$ aos 20 de diferença de idade. ${ }^{13}$ Charlotte usou um vestido de veludo vermelho, casou-se sem festa e no final de sua vida definiu o casamento como o único caminho possível para romper com algumas determinações.

É interessante a narrativa da transformação pessoal, espacial, corporal desses anos: para decorar seu apartamento de mansarda, Charlotte sentia-se livre dos constrangimentos da escola e das lojas, pois criava para ela mesma. Nesse momento ela viu Josephine Baker em Revue nègre, "uma Josephine negra, nua, ao ritmo descadenciado, com o pescoço adornado por bananas, uma mulher selvagem, autêntica" (Perriand, 1998:23). É o momento da descoberta do jazz, do charleston, da literatura inglesa. Ela cortou os cabelos à la garçonne e mandou fazer um colar de bolas de cobre cromado, "um símbolo e uma provocação que marcava meu pertencimento à época mecânica do século XX" (idem), ao mesmo tempo em que se iniciou no alpinismo e outros esportes de montanha. Passou a personificar a imagem da mulher moderna descrita por Le Corbusier ${ }^{14}$ : uma mulher de cabelos curtos, que se veste em cinco minutos e é bela, seduz por sua

${ }^{13}$ Segundo sua autobiografia, o vestido vermelho era para evitar rendas $e$ adereços, e o casamento a possibilidade da lagarta virar borboleta, ao que acrescentou: mas "a borboleta voa" (Perriand, 1998:22).

14 "A mulher nos precede. Ela realizou a reforma de seu traje. Ela encontrava-se num impasse: seguir a moda e então renunciar à contribuição das técnicas modernas, à vida moderna. Renunciar ao esporte e, problema mais material, não poder aceitar empregos que lhe permitiriam ter uma participação fecunda na atividade contemporânea e ganhar sua vida. Seguir a moda: ela não podia pensar em guiar; não podia nem o metrô, nem o ônibus, não podia sequer agir com desenvoltura em seu escritório ou na loja. Para poder realizar a construção cotidiana de sua toalete - pentear-se, calçar o sapato, abotoar o vestido - ela não tinha mais tempo para dormir. Então a mulher cortou seus cabelos, suas saias e suas mangas. Agora está com a cabeça descoberta, os braços de fora e as pernas livres. Veste-se em cinco minutos. E é bela, seduz com o encanto de suas graças, das quais os modistas resolveram tirar partido." (Le Corbusier, 2004 [1930]:112). Adiante, no mesmo texto, ele volta ao tema, mas dessa vez enfatizando discretamente um atributo de sedução: "A mulher moderna cortou os cabelos. Nossos olhares conheceram a forma de suas pernas." (idem:125) 
Corpos, cadeiras, colares

graça, coragem com seu espírito de invenção que operou a revolução na indumentária, um milagre dos tempos modernos. Segundo o depoimento de sua amiga Marianne Clouzot, seu marido Scholenfield exibia sua parisiense moderna como um trunfo.

Seja por conta das críticas recebidas, pelo casamento ou pelo contraste com a obra mais arrojada de Djo-Bourgeois, o que sabemos é que seu trabalho se alterou. Em 1927 no Salon d'Automne, Charlotte apresentou um Bar sous le Toit, sob o teto, título que pode ter implicações sociais (Costa Meyer, 2003:26) se pensamos que destinava-se à mansarda de um edifício parisiense, ainda que a obra não fosse endereçada aos mais pobres. Além disso, era um bar, com mesa de jogo - ambiente masculino desenhado por uma mulher que era autora, cliente e usuária: o bar de mansarda foi desenhado para o apartamento que ela dividia com o marido no lado mais boêmio de Paris. Mais do que a ruptura com a ideia de genius loci, assinalada por Costa Meyer (2003:30), foi sua ruptura - e aqui sou eu a dizer - com idéias préconcebidas de domesticidade. $\mathrm{O}$ apartamento chamou a atenção da imprensa e foi publicado na Révue de la Femme como um espaço que seduzia por sua coqueteria.

Se o casamento lhe assegurava condições de trabalho, a mudança estética veio com relação profissional com um homem que se colocava no centro do campo da arquitetura moderna Charles Edouard Jeanneret, mais conhecido como Le Corbusier. Foi o joalheiro Jean Foquet quem emprestou a Charlotte os programáticos e panfletários Vers une Architecture e L'art decoratif d aujourd hui. A leitura significou uma alternativa ao art-déco ao mencionar o papel da indústria na casa, na famosa máquina de morar.

Aparentemente, a visita frustrada - Le Corbusier a rejeitou dizendo que ali não se bordavam almofadas - de Perriand ao ateliê da rue de Sèvres aconteceu poucos dias depois da 
Silvana Rubino

exposição Weisennhof Siedlungen de Stuttgart. ${ }^{15}$ Nessa exposição de habitações de fato construídas, a cozinha foi o centro das atenções, com as regras gerais definidas por uma Associação de Donas de Casa de Stuttgart e pelo livro Der neue Haushaut, livro de 1926 da feminista Erna Meyer sobre a "nova casa" que vendeu vinte e nove edições em dois anos, e que vinha ilustrado com casas construídas por arquitetos ligados ao Neues Bauen e com equipamento projetado pela Bauhaus. A casa apresentada por J.J.P. Oud era um exemplo desse novo ideal de casa eficiente. Confiante em seu charme e seus desenhos, Perriand ouviu que naquele ateliê não se bordavam almofadas, mas ao visitar o Salon d'automne, Le Corbusier visitou o Bar sous le toit e reconsiderou sua grosseira recepção, convidando-a para desenvolver o desenho de mobiliário que ele preconizava desde o pavilhão Esprit Nouveau de 1925.

A nouvelle femme de 23 anos que Corbusier aceitou sem remuneração, mas com o status de associada ${ }^{16}$ se apresentava então como "Perriand-Scholenfield, Meubles, 74, rue de Bonaparte" e seu apartamento tornou-se um grande laboratório, uma oportunidade de se distinguir das criações em madeira, tapeçaria e outros saberes artesanais. Ela concluiu em 1928 uma sala de jantar, recriada e exibida no Salon des artists décorateurs do mesmo ano, junto a um salão de Djo-Bourgeois (1898-1937) e

\footnotetext{
${ }^{15}$ Exposição dirigida pelo arquiteto Mies van der Rohe que consistia em trinta e uma edificações projetadas por dezessete arquitetos, incluindo blocos de apartamentos do próprio Mies, de J.J.P. Oud e de Mart Stam, e diversas casas, sendo duas de Le Corbusier e de seu primo e parceiro Pierre Jeanneret. Segundo Mary McLeod (2003:37), os interiores das casas alemãs eram elegantes, enquanto Le Corbusier não dava conta de equipar suas casas à altura de seus projetos arquitetônicos. Nesse caso, no último momento, seu parceiro Alfred Roth desistiu de esperar os projetos de equipamento que não chegavam $e$ improvisou, com um resultado que contrastava muito com o interior do apartamento de Mies, projetado em parceria com Lilly Reich - outra designer que precisa ser estudada. Le Corbusier foi severamente criticado pelos alemães.

${ }^{16}$ Ela tinha o status de associada e ao mesmo tempo tinha aulas particulares de arquitetura com Alfred Roth, atividade financiada por seu marido.
} 
Corpos, cadeiras, colares

um fumoir de René Herbst (1891-1982). O grupo decidiu expor junto para produzir o que denominaram "unidade de choque" $e$ Elisa Djo-Bourgeois desenhou as cortinas e os tapetes da sala do marido. As cadeiras da sala de Perriand eram visivelmente inspiradas por cadeiras de escritório e a revista, L`Architeture, considerou o trabalho do grupo de extrema esquerda e um artigo publicado pela revista feminina Maison pour Tous, descreveu o projeto como adequado a uma existência ativa, sem grandes períodos de repouso, enfatizando ser de autoria de uma mulher que usava colares de metal e cabelos curtos - não era a sala de jantar da tradicional femme au foyer. McLeod enfatiza que parte do sucesso pode se dever a uma atenção de Perriand aos detalhes, elegância e outros atributos tradicionalmente femininos, observação que ela faz a partir dos adjetivos usados pela imprensa para qualificar o trabalho: charmoso, jovem, gaï: uma feminilidade em termos modernos, que pode ter facilitado a recepção de uma agenda renovadora (McLeod, 2003:44). A sala de jantar era composta de uma cadeira pivotante (siège tournant) e de uma mesa extensível coberta de borracha, que ao contrário da cadeira, nunca recebeu a assinatura tripla Corbusier-Jeanneret-Perriand. A aceitação $e$ a associação não apagaram totalmente a tensão inicial, sem dúvida atravessada por questões de gênero: quando Charlotte convidou Corbusier e seu primo Jeanneret para uma visita ao seu apartamento, na qual os surpreendeu com algumas cadeiras prontas, ouviu do primeiro: "Ils sont coquets".

Charlotte Perriand expunha nos salões refinados, saudados pela imprensa e não no Salon des Arts Menagers, fundado em 1923 por Jules-Louis Breton, um engenheiro socialista simpatizante da aplicação dos princípios tayloristas ao mundo doméstico. Tal debate a respeito da racionalização das tarefas cotidianas foi levado a cabo pelas alemãs no mesmo período, resultando no projeto da cozinha de Frankfurt, de 1926-7. Por conta da situação da indústria francesa, se comparada à americana e alemã, não é seguro falarmos em um desenho industrial, especialmente se tomarmos as anotações de Charlotte a 
respeito dos artesãos que deveriam executar seus desenhos. Nesse momento, ainda menos comprometida com os aspectos sociais daquilo que desenhava, ela se projetava como uma mulher moderna em seu corpo e seus projetos de mobiliário - a diferenciação em relação a Corbusier, especialmente no que toca opções políticas viria apenas na década seguinte.

Chegamos assim à cadeira mencionada no início do artigo, na qual Charlotte se fez fotografar, a chaise-longue que permite várias posições, inspirada em cadeiras de balanço em madeira $e$ também em uma cadeira médica para repouso patenteada como Surrepos. Esta obra foi a culminação dos anos em que trabalhou em parceria com Corbusier e Jeanneret: na foto vemos Charlotte deitada em sua chaise-longue em foto concebida por ela e clicada por Pierre Jeanneret na ausência de Corbusier, que estava no Brasil. Suas pernas erguidas contrastam com a delicadeza dos sapatos boneca, seu colar-manifesto em bolotas de metal é uma afirmação de modernidade - ela usou essa foto para ilustrar um manifesto ao qual voltaremos - enquanto candidamente esconde seu rosto. Já no final de sua vida, a leitura feminista que a historiadora da arquitetura Beatriz Colomina fez dessa imagem, sugerindo que ela olhava a parede e nada enxergava, negando sua visão e autoria (Colomina, 1992:106-7), deixou Perriand, já mais do que consagrada, especialmente zangada, argumentando que tudo que ela queria era enfatizar a cadeira, que poderia ser usada por qualquer um. Mas, nota McLeod, com suas pernas para o alto, seu vestido, sim, ela era coquete, ao exibir um móvel que, como sua imagem, tinha um charme ligado à sedução. A foto tem duas versões, com roupas diferentes. Foi tirada por Pierre Jeanneret enquanto Le Corbusier visitava a América do Sul ${ }^{17}$, e ilustrou o segundo volume da Oeuvre do arquiteto, assim como o artigo "Wood or metal?" que Charlotte publicou na revista inglesa

${ }^{17} \mathrm{Na}$ sua décima conferência em Buenos Aires, em 19 de outubro de 1929, Le Corbusier creditou à Charlotte a importância da revolução do mobiliário, dizendo que enquanto ele ali falava, ela demonstrava no Salão de Outono o princípio do equipamento de uma casa moderna (2004 [1930]:118). 
Corpos, cadeiras, colares

Studio defendendo o metal, que segundo ela realizaria no mobiliário a mesma revolução que o cimento havia logrado na arquitetura. $\mathrm{O}$ artigo, que a apresentava como uma "campeã de idéias novas", concluía pedindo transparência, azuis, vermelhos, espaço, luz, e antecipando a má sorte daqueles que não se mantêm em boa forma física e mental - em outras palavras, daqueles que não fossem homens do século $\mathrm{XX}$. Contido, de certo modo, e contrastando com a irreverência do texto, o artigo trazia Charlotte fotografada em outra posição, com as pernas abaixadas; de resto, a foto é semelhante: rosto virado contra a câmera, braços inertes ao lado do corpo, mas há sem dúvida um pudor maior do que na foto com as pernas, embora cruzadas, erguidas. Ainda que as duas fotos possam ter sido produzidas para mostrar a versatilidade da cadeira - expediente também utilizado por Lina a escolha em cada situação diz muito.

Charlotte desempenhou um papel central no ateliê da rue de Sèvres, especialmente nos períodos em que Le Corbusier se ausentava em razão de suas viagens - como as conhecidas para o Brasil, em 1929 e 1936. Nessas ocasiões, cabia a ela e a Jeanneret a responsabilidade por projetos, como por exemplo, o pavilhão Temps Nouveaux de 1937. Na mesma mostra, ela construiu com Ferdinand Léger o Pavillon de l'Agriculture, totalmente afinado com a esquerda francesa e o Front Populaire. Durante os dez anos em que trabalhou com Le Corbusier e Pierre Jeanneret, foi responsável pelo equipamento interior de todas as construções da dupla de arquitetos (Benton, 2005:15). Em 1937 ela seria convidada a se retirar do ateliê, por sua presença disruptiva, um elemento perturbador - foi a justificativa que recebeu de Corbu. Até que ponto suas opções políticas, a proximidade afetiva que ela, divorciada de Scholenfield, mantinha com Pierre Jeanneret teriam prevalecido nessa decisão? $\mathrm{O}$ fato é que Le Corbusier nesse momento parecia ideologicamente mais próximo de quem trabalharia em Vichy, enquanto Jeanneret se lançaria na resistência francesa e Charlotte viajaria para o oriente, 
Silvana Rubino

desdobramentos - no Japão ela redesenhou a chaise em bambu que apenas assinalo para tratar oportunamente.
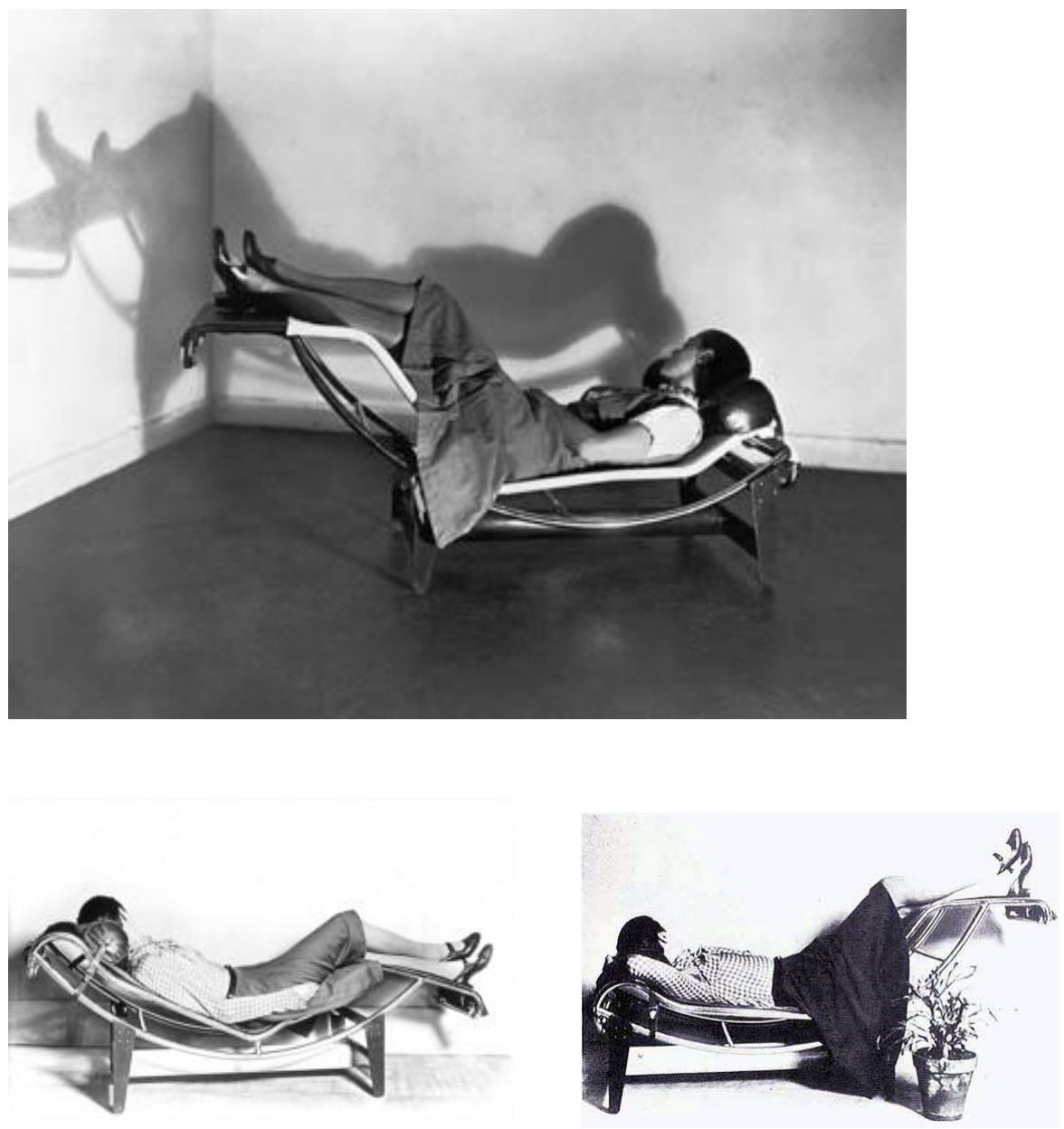
Corpos, cadeiras, colares

LINA BO BARDI

Acchilina di Enrico Bo nasceu em 1914, em um bairro burguês residencial de Roma. Diferente de Charlotte, de família mais modesta e que se fez batizar aos 18 anos, foi batizada muito próxima de sua casa: no Vaticano. Seu pai era um engenheiro civil, empreendia construções e era pintor de domingo. Foi Enrico Bo que ensinou sua primogênita a desenhar e o empenho familiar era no sentido de que após o término do Liceu Artístico ela cursasse Belas-Artes. Na Roma tomada pelo fascismo, aconselhada pelo pai, Lina, como a chamavam, cursou o Liceu por quatro anos e ao mesmo tempo contrariando e confirmando a disposição familiar, ingressou na Università degli studi di Roma, onde era uma das duas mulheres - e a pesquisa jamais descobriu quem era a outra. ${ }^{18} \mathrm{Em}$ pleno fascismo, eram arquitetos de renome e vinculados ao regime que dirigiam o curso: Marcello Piacentini, o autor da cidade universitária de Roma e Gustavo Giovanonni, o teórico maior da restauração naquele período.

Para se formar em arquitetura em Roma, Lina Bo apresentou como trabalho final de curso, um hospital-maternidade de arquitetura moderna. Além da nota relativamente baixa, foi desqualificada pelo diretor da escola, Marcello Piacentini, que teria dito que uma bella ragazza como ela terminaria se casando, e portanto estaria fora do exercício da arquitetura. A violência simbólica desse ato é simétrica à desqualificação sofrida por Charlotte no episódio do "bordar ou não almofadas", uma enunciação da norma de gênero que desqualifica e desinveste. Formou-se em 1939, com 25 anos.

Mas foi um pouco nos espaços femininos que Lina, recém formada e trocando sua Roma natal por Milão, começou seu exercício profissional fazendo ensembles, muito em parceria com

${ }^{18}$ A trajetória de Lina Bo Bardi em Roma, Milão, São Paulo e Salvador, até a inauguração do MASP, em 1968, está detalhada e analisada em Rubino (2002 e 2009). 
o colega Carlo Pagani, e ilustrando revistas, ainda que tivesse, com a ajuda financeira de seu pai, aberto um escritório. Lina foi trabalhar, sem remuneração, com o camaleônico arquiteto Giò Ponti: editor, autor de edifícios importantes, designer e promotor do artesanato italiano, seu escritório dedicava-se, dentre tantas tarefas, à organização das Trienais de Artes Decorativas. Um projeto de decoração de interiores, realizado em parceria com Pagani chegou a ser executado em $1942 .{ }^{19}$ A revista Quaderni di Domus, que Lina fundou - também com Pagani - em 1945, dedicava-se aos problemas da casa moderna - da porta para dentro, ao que tudo indica - e nela eram publicados os melhores exemplos, italianos ou não, de mobiliário e equipamento doméstico (Campello, 22). Em 1946, Lina viajou por toda a Itália pesquisando artesanato, com o fim de organizar uma exposição de têxteis para cortinas e estofamentos para uma empresa italiana, a Rima. Não por acaso, já no MASP, estaria envolvida com a criação de uma escola de desenho industrial, o Instituto de Arte Contemporânea (IAC).

Em uma revista que fundou em 1945 com Bruno Zevi - A, ou Cultura della Vitta - Lina propunha um jogo que ensinava o leitor a usar a casa e os objetos modernos. Tratava-se sempre da escolha de um copo, um relógio doméstico, um adorno. A resposta "errada" era severamente criticada como falta de visão funcional e estética. No mesmo periódico, que durou apenas nove meses, ela editou um artigo a respeito da liberdade feminina no século $\mathrm{XX}$, liberdade solucionada por meio de equipamento doméstico e de uma cozinha americana. O pós-guerra italiano era de reconstrução e este país teve um lugar central na redefinição do modernismo arquitetônico que traria novos temas como identidade e centros urbanos e culminaria na dissolução dos CIAMs no final dos anos 1950. E enquanto Charlotte descobria o

${ }^{19} \mathrm{O}$ "Projeto de ambientação de apartamento em Miláo" foi publicado em Lo Stile, revista dirigida por Ponti, em 1942. Foi seu único projeto executado no período em que exerceu a profissão na Itália. 
Corpos, cadeiras, colares

Japão e trocava o aço pela madeira, Lina migrava para o Brasil para iniciar sua carreira de architetto, como ela dizia, em italiano $e$ sem flexionar.

Casada com o jornalista, crítico e comerciante Pietro Maria Bardi, pode acrescentar a essa sina de ambientadora de cenários interiores outros ramos da arquitetura. A narrativa posterior a respeito do casamento de Lina assemelha-se àquela de Charlotte, algo como "casei, ele era moderno", sem evidenciar em nenhuma fala a centralidade desse consórcio na carreira que desenvolveu posteriormente e pouco enfatizando a potência dessa parceria. Embora de origens sociais distintas e aparentemente apartados por posições políticas - Bardi foi uma peça importante na política cultural de Benito Mussolini enquanto Lina freqüentava mais a esquerda milanesa - Pietro e Lina Bardi compartilhavam uma aposta quase irrestrita na arquitetura moderna e um apreço pela arte popular brasileira, além de editarem juntos a Habitat, revista do museu. Em 1951, concluiu a própria casa chamada, como tantas outras, Casa de Vidro ${ }^{20}$, seu laboratório de experimentações conferidas pela autonomia - ela escreveu na Habitat que nessa casa o cliente era o próprio arquiteto. No mesmo bairro do Morumbi, projetou posteriormente uma casa para a amiga Valeria Cirell e, ainda em 1958, iniciou o projeto para a futura sede do Museu de Arte de São Paulo - cujos interiores ela já havia ambientado quando de sua fundação em 1948, chegando a projetar móveis, pois não se satisfez com o que encontrou no mercado brasileiro.

Assim, de certo modo, Lina enfrentou aqui os mesmos dilemas de produção com os quais Charlotte havia se deparado duas décadas antes: a relativa letargia da indústria em relação ao mobiliário. Se na Paris de 1920-30 não havia quem executasse os desenhos de Perriand até estes serem, finalmente, assumidos pela

${ }^{20}$ Casas de vidro são uma constante. A primeira, Maison de Verre, foi construída em Paris entre 1928 e 1930, combinando as funções de uma clínica médica e uma casa particular. 
empresa Thonet, em 1948, Lina fundou com Bardi e seu amigo arquiteto conterrâneo Giancarlo Palanti o Studio Palma e a fábrica de móveis Pau Brasil, que terminaram por fechar suas portas por dificuldades de produção. E para sua Casa de Vidro projetou a poltrona batizada de Bardi's Bowl. Como Charlotte, foi modelo de seu trabalho, emprestou seu corpo, sua imagem à sua obra. Inclusive para uma propaganda do loteamento Jardim Morumbi, de 1952, na qual aparece na Casa de Vidro mirando uma mata Atlântica inexistente, numa montagem fotográfica.

A Casa de Vidro não foi bem recebida por críticos italianos por ter dependências de empregada. Giò Ponti disse que havia ali um segredo, uma vinculação da italiana Lina aos problemas insuperáveis do Brasil, à aceitação do trabalho servil. O "segredo" era apenas o desconforto europeu com uma área que, nos edifícios parisienses haussmanianos, ficava na mansarda dos empregados domésticos aos quais Le Corbusier se referia no mesmo estatuto de equipamentos e máquinas.

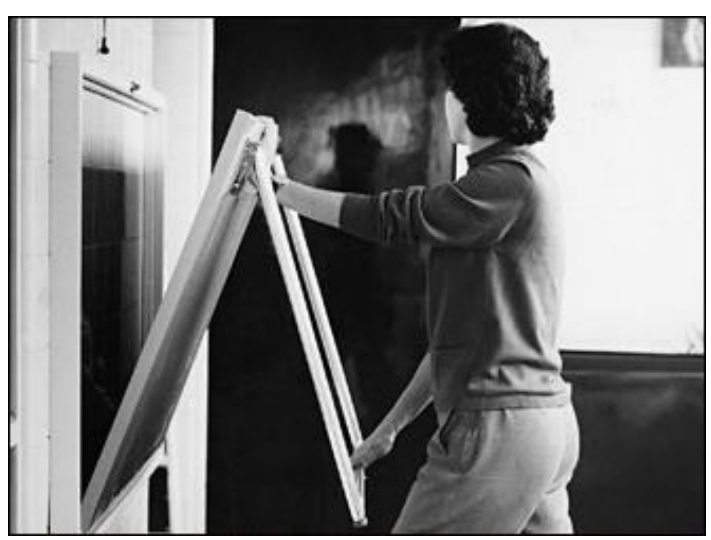


Corpos, cadeiras, colares

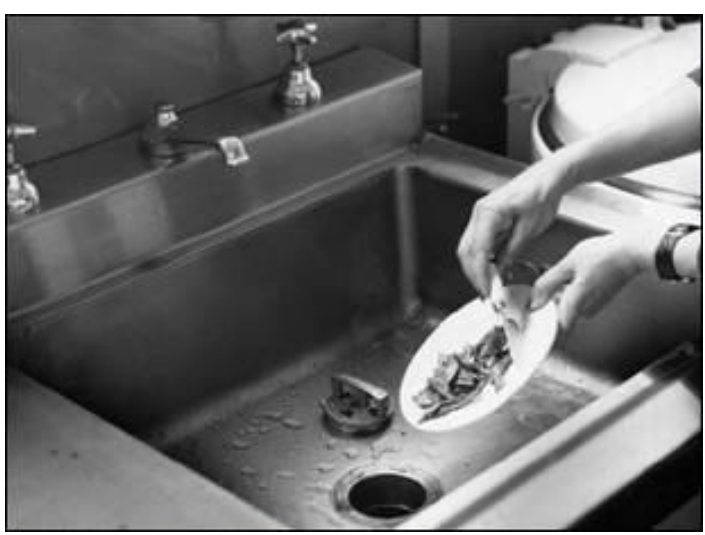

Mas foi pouco depois, em uma Enciclopédia da mulher, na qual ela aparece como autora de um verbete, que essa exposição como mulher moderna que sabe usar os espaços modernos chegou àquele que é talvez, seu ponto máximo. Nesse verbete, uma cozinha americana (mostrando equipamento ainda não conhecido no Brasil) exibida era a de sua casa, jamais usada por serem máquinas muito sofisticadas para os empregados manejarem. Lina era a mulher moderna, mas seu texto pode ser inserido numa linhagem de ensinamentos para donas de casa, como os que ela já escrevia com Carlo Pagani em Milão nos anos 1940, assim como dos manuais da vida doméstica.

Em 1915, nos Estados Unidos, Mary Peterson publicou Principles of Domestic Engineering e Christine Frederick seu Scientific Management in the Home. O livro de Frederick baseavase nos "Doze princípios do gerenciamento científico" definido pela Lillian Gilbreth para a mulher que trabalhava em sua própria residência. A idéia era um seqüencia de atividades na ordem certa, mas central a ela estava a proposta de que a cozinha deveria ser um espaço apenas para se cozinhar, e portanto poderia diminuir de tamanho. Menor, ela exigiria menos movimentos para a execução das mesmas tarefas. Os arquitetos europeus logo identificaram essa cozinha como a marca registrada dos cuidados científicos com o lar - isso em um momento no qual 
Silvana Rubino

a arquitetura moderna propunha uma nova casa, uma máquina, um novo modo de se morar. ${ }^{21}$

Ao final dos anos 1920 na Alemanha, a divulgação das idéias do novo modo de se gerenciar uma casa, aliada à atuação de arquitetos como Bruno Taut gerou como solução a proposta da casa para uma subsistência, ou existência mínima (Die Wohnung für das Existezminimum). E a culminação disso tudo foi o projeto da conhecida Cozinha de Frankfurt, pela arquiteta austríaca Grette Schütte-Lihotsky ${ }^{22}$, exibida na Die neue Wohnung und ihs Innesausbau, em 1925, e logo incorporada em diversos projetos residenciais construídos nessa cidade por Ernst May. Trata-se de uma Kochküche, cozinha para se cozinhar, pequena e com uma aura de modernidade que vinha do uso da eletricidade. A novidade atravessou de volta o Atlântico e, em 1934, o livro Modern Housing, de Catherine Bauer e editado em Nova York saudava a cozinha de Schütte-Lihotsky como uma das grandes conquistas da nova arquitetura (Bullock, 1988:188).

${ }^{21}$ Um artigo publicado na revista $A$ (depois rebatizada como Cultura della Vitta), editada em Milão, em 1946, por Lina Bo (futura Bardi) intitulava-se "Puo Il huomo essere libero si la Donna e uma schiava?". O artigo, assinado por RGM, tomava de empréstimo uma frase do poeta romântico P.B. Shelley (Can man be free if woman be slave?), ressaltando, contudo que não se tratava de tirar a mulher de sua posição familiar, mas de liberá-la de sua antiga fadiga com ajuda da educação e das modernas descobertas científicas. O artigo seguinte, no mesmo número intitula-se "La cucina dell'avvenire" e menciona uma cozinha projetada pela empresa norte-americana Libbey Ovens Ford, tão distinta da cozinha italiana do momento, diz o artigo não assinado, como a abóbora da carruagem de Cinderela. $\mathrm{O}$ artigo trazia imagens de uma mulher bem arrumada e de avental utilizando batedeira elétrica e outras novidades. Ver $A n^{\circ} 1$. Editoriale Domus, fevereiro de 1946.

22 Margarete Schütte-Lihotsky (1897-2000) foi a primeira mulher a se formar em arquitetura na Áustria. Estudou com Joseph Hoffman e trabalhou com Adolf Loos, além de Ernst May, quando ele era o arquiteto responsável pela habitação na prefeitura de Frankfurt. Grete, como era chamada, equipou com sua cozinha planejada mais de 10 mil unidades habitacionais. A Cozinha de Frankfurt foi concebida levando em conta a quantidade de movimentos realizada pelo corpo no preparo dos alimentos. 
Corpos, cadeiras, colares

A casa de Lina e Pietro Bardi, como muitas das projetadas no século XX por arquitetos reconhecidos, era uma exibição: além de moradia, era um passe de entrada no campo da arquitetura brasileira. A Casa de Vidro não foi projetada para nenhuma mostra, mas há indícios de que ela poderia ter sido um ateliê ou uma residência para artistas convidados pelo MASP. Se para Charlotte, seu primeiro apartamento, financiado por seu marido, era um laboratório, para Lina, sua casa, projetada nas mesmas circunstâncias de autonomia financiada por seu parceiro, é como a Ville Savoye (de Le Corbusier) e outras residências consagradas - um manifesto "por uma arquitetura".

E nessa casa, usada como exemplo de um morar moderno (os outros exemplos são casas projetadas por Vilanova Artigas), as imagens mostram uma mulher "moderna" que escapa ao padrão iconográfico do período. Lina está de calças compridas, de relógio, não porta vestidos ou aventais. A cozinha poderia se assemelhar à funcional cozinha americana, uma versão mais espaçosa e mais equipada da cozinha de Frankfurt - afinal era uma casa burguesa, enquanto a segunda destinava-se a conjuntos habitacionais - mas ela não representava a dona de casa suburbana do Kitchen Debate que ocupou a América do Norte no auge da guerra fria. Os empregados domésticos, mencionados no texto, não têm suas dependências mostradas nas fotos e desenhos que ilustram o verbete.

A cozinha era alemã e americana, distante das tradições do espaço doméstico burguês nas cidades brasileiras. Seu mobiliário, porém, mesclava chita com madeiras locais - cujos veios a encantaram e mais tarde viriam a encantar Charlotte Perriand ainda que a Bardi's Bowl fosse de metal e couro, numa vinculação com os móveis europeus dos anos 1920 e 1930, mas dialogando com o que arquitetos e moveleiros modernos faziam então em São Paulo. E também Lina em algum momento dedicou-se a fazer um colar para si. O colar de águas marinhas, com o qual compareceu ao baile do Instituto dos Arquitetos em 1948, recém chegada a São Paulo, foi um manifesto de naturalização, de 
assimilação ao Brasil, ao usar (e enunciar isso) deliberadamente pedras brasileiras e semi-preciosas, e também um modo de se diferenciar das mulheres com as quais convivia socialmente no período de fundação do MASP da rua 7 de abril. Diferente do colar da jovem Perriand, um manifesto a favor da industrialização e do metal que ela por muitos anos no início de sua carreira usou, com seus cabelos tosados para compor sua imagem de mulher moderna. Com ele deixou-se fotografar em diversas ocasiões, inclusive em posição de repouso na sua mais conhecida cadeira. O colar de Lina era uma plataforma por um desenho de jóias brasileiras, de bronze, prata, quartzos e berilos, algo fora dos "brilhantões das madames". Um projeto que era o mesmo para o design, para os museus, com a diferença de que ela o portava publicamente em seu colo.

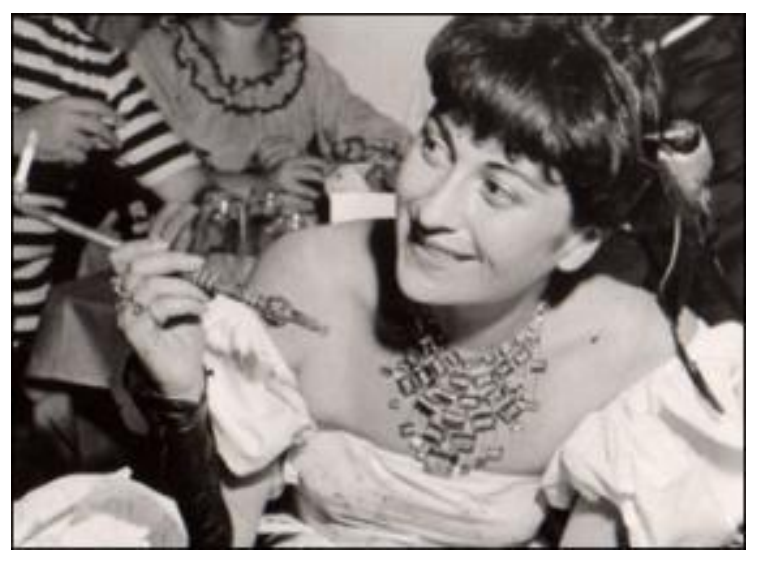


Corpos, cadeiras, colares

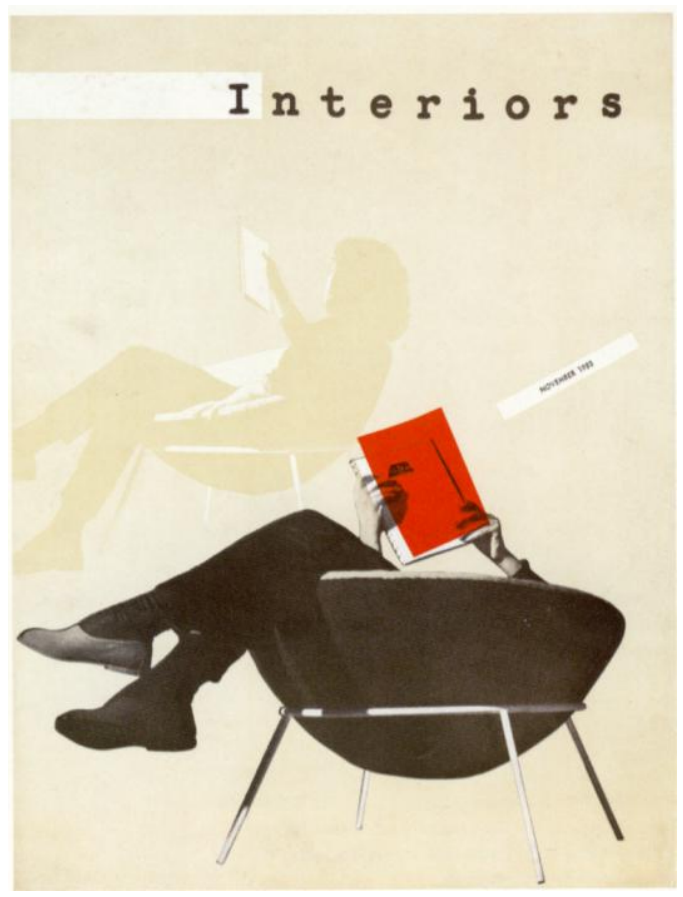

Considerações finais

Há uma hierarquia nas artes: a arte decorativa está embaixo, a figura humana, no topo.

Ozenfant e Jeanneret (Le Corbusier"), Depois do cubismo.

Briony Fer observa, em seu trabalho sobre os construtivistas russos, a presença feminina numa arte "útil". Mulheres como Varvara Stepanova trabalhavam em construções que ficavam entre a indústria, universo masculino, e certos aspectos da arte popular, como o bordado, que implicavam o feminino. Além de participar das chamadas artes menores, o trabalho feminino, 
Silvana Rubino

naquele espectro advogado por Gropius, redesenhou a casa, o interior, a vida doméstica, que nunca mais foi a mesma.

Mary McLeod (1996:20) chama a atenção para o conceito de heterotopia desenvolvido por Foucault em sua palestra "Des espaces autres", de 1967. O espaço heterotópico, distinto do utópico, assim como da paisagem cotidiana, nos fornece uma percepção nítida da ordem social: prisões, hospitais, igreja, bordel etc. Ao contrário das utopias, as heterotopias são lugares identificáveis, que permitem uma relação com o tempo diversa daquela dos espaços cotidianos. Contudo, argumenta McLeod, a heterotopia exclui espaços infantis e femininos, lugares nos quais as mulheres encontraram não apenas opressão como também conforto e mesmo autonomia. A exclusão da casa, por ser um "lugar de repouso", diz a autora, pode ser uma definição de difícil aceitação para qualquer mãe que ali trabalha. A autora nos empresta uma chave sugestiva para nos indagarmos, afinal, para que mulher os interiores modernos foram projetados: para a mulher que trabalha, para a "rainha do lar"?

Voltemos às fotografias. Dificilmente as fotos de arquitetura desse período mostram pessoas nos projetos construídos, mostram usos. Mesmo nos espaços domésticos, salas e cozinhas parecem passíveis de ocupação, ainda que dificilmente uma figura humana apareça sugerindo como fazê-lo. Nos desenhos técnicos, o elemento humano é totalmente ausente, e nos croquis aparecem para dar sentido de proporção, a conhecida "escala humana". Vale a pena nos determos um pouco nesse ponto, não porque nos desenhos de Lina, posteriores ao seu repouso na Bardi's Bowl, há sempre uma idéia dos usos e ocupações, mas porque a própria noção de escala, de corpo como medida é particularmente interessante, pois no século XX foi parte de um "retorno à ordem" nas artes maiores e menores européias, de uma adaptação das artes funcionais à indústria e à chamada vida moderna.

Elas usaram corpos, seus corpos, como medida para um móvel que elas redesenharam e que até então era classificado como um móvel masculino. A cadeira Surrepos que pode ter 
Corpos, cadeiras, colares

servido de modelo para a chaise-longue tinha seu uso demonstrado por um homem e suas primeiras cadeiras, como já foi dito, foram inspiradas em cadeiras de escritório. Vania Carneiro de Carvalho mostra como poltronas são parte dos espaços masculinos da casa, em oposição aos sofás, exatamente porque as primeiras permitiam apenas uma pessoa sentada, o homem da casa, compenetrado ou se recuperando do trabalho no ambiente exterior, em oposição ao sofá, cujas qualidades eram mostradas com uma mulher ali sentada com sua prole. Lina Bo Bardi jamais desenhou um sofá e não havia um na Casa de Vidro, embora um croqui mostrasse um móvel ou um degrau na sala onde estão sentados ela - de calças compridas -, Bardi, uma terceira figura masculina e um gato. Estariam nessas fotos, Lina e Charlotte tomando posse do móvel destinado ao homem, o repouso que remete ao trabalho no espaço público, revertendo a teatralidade do espaço doméstico, propondo uma nova?

O termo teatralidade é intencional. A divulgação da Bardi's Bowl mostrava uma atriz reconhecidamente bela, Odete Lara, com as pernas cruzadas, elegantemente trajada e calçada, usando jóias e com o rosto ligeiramente virado, de olhos cerrados. A cadeira foi capa da revista norte-americana Interiors e traz duas imagens de Lina, uma como figura e outra como fundo, como marca d'água: nas duas imagens Lina está lendo. A de fundo esconde o rosto e tem os pés no chão; na que sobressai, temos suas mãos, pernas e um livro, em cor contrastante.

Sentar-se, lembra Carvalho, mais do que mera prática corriqueira, é um "gesto socialmente significativo e, por isso mesmo, sexualmente ativo" (2008:195). Os manuais de etiqueta que a autora analisa, em um período um pouco anterior ao de nossa primeira foto, dão especial atenção à posição de pernas $e$ pés femininos. Elas se deixaram fotografar entregues ao conforto repousante de suas cadeiras, ou ao enredo de um livro em uma foto onde não temos sequer o rosto das leitoras. Não há rigidez muscular nas pernas de Lina e Charlotte, como convinha (convém?) às mulheres. $\mathrm{E}$ ao contrário das conhecidas cadeiras 
desenhadas pela Bauhaus, essas fazem mais pensar em repouso do que em trabalho. ${ }^{23}$ As cadeiras eram inusitadas para o momento, assim como as que nela sentavam, mostrando-se de corpo inteiro e ocultando o rosto. Mas, ao posar em suas cadeiras, a quem dirigiam as respectivas imagens? Ao futuro comprador, usuário ou ao interlocutor que também era um produtor de objetos para vida moderna? Se esse último interlocutor esteve em jogo, é preciso lembrar que, assim como quadros, fotos devem muito à observação de outras fotos, e estas certamente estão informadas por uma longa série de imagens em circulação, que desde os anos 1920 mostravam, em revistas e outras publicações, o que era a mulher moderna - um espectro que vai das imagens dos manequins de Poiret até as fotos que o surrealista Man Ray fez da modelo Lee Miller.

Há sugestões, indícios de que Lina e Charlotte se conheceram em algum momento no Rio de Janeiro dos anos 1950, e em sua autobiografia a segunda declara sua admiração pela primeira, ao conhecer o Solar do Unhão em Salvador. Trabalhando distantes no espaço, com dez anos de diferença, elas partilhavam do contato com figuras centrais nas tramas do chamado movimento moderno. Charlotte estava no navio no qual se realizou o CIAM de 1933, assim como Pietro Maria Bardi, que também era amigo de Le Corbusier. Em algum momento, ambas tiveram contato com Lucio Costa. No segundo pós-guerra, as já um tanto consagradas Charlotte e Lina manifestavam mais interesse pela cultura popular e pela madeira do que pela industrialização e por cadeiras de metal. Essa mudança de perspectiva era em certa medida marcada pelo contato com o Japão e Indochina, no primeiro caso, e com a Bahia e o Nordeste brasileiro, no segundo. Mas o encontro físico, situado, entre elas, tenha ou não acontecido, pouco muda: suas trajetórias se encontram, se interceptam em pontos, atando nós delicados $e$

${ }^{23}$ Como notou Mary McLeod, as cadeiras de Charlotte não freqüentam tanto os espaços corporativos como suas equivalentes da escola alemã. 
Corpos, cadeiras, colares

sólidos. Seus lugares no campo da arquitetura moderna e das chamadas vanguardas eram pré-determinados, assim como para outras arquitetas e artistas modernas. Determinação explícita, como na Bauhaus de Weimar, onde e quando as mulheres ingressantes eram diretamente conduzidas para as oficinas de tecelagem e de cerâmica (Droste, 1990:40); ou sutil, silenciosa, incorporada. $\mathrm{O}$ que nos convida a observar as obras, a procurar nelas as tensões de gênero que marcaram suas trajetórias, que, tudo parece indicar, conferiu às mulheres um lugar no menos valorizado espaço doméstico e no âmbito das chamadas artes menores. Não por acaso, a engenheira Carmen Portinho foi a fundadora da Escola Superior de Desenho Industrial no Rio de Janeiro. Mas Carmen seria tema para outro artigo.

Seria forçar demais a premissa de uma pesquisa em curso afirmar que cadeiras e móveis foram definidos, internamente ao mundo dos arquitetos modernos como assunto de mulher. Bastaria mencionarmos as conhecidas cadeiras produzidas pela Bahuaus, como a Wassily, do arquiteto Marcel Breuer, para derrubarmos tal argumento. $\mathrm{E}$ sabemos que, confinadas às oficinas de têxtil e louça, Anni Alpers, Marianne Brandt e outras contribuíram para borrar as fronteiras entre gêneros artísticos. Por enquanto, encerramos com uma imagem da cadeira de Breuer, na qual a modelo, possivelmente aluna da Bauhaus, empresta seu corpo feminino para exibir as qualidades da cadeira. Não olha para a parede, como Charlotte, nem se oculta atrás de um livro como Lina. Usa, sim, uma máscara, como modo de se tornar anônima. Sabemos apenas quem projetou a cadeira e a máscara Oskar Schlemer - mas não quem é a modelo. Por outro lado, o nome de Charlotte esmaeceu por trás de uma denominação - LC4 - atribuída a Corbusier ou, quando muito, a ele, Jeanneret $e$ Perriand. Ainda assim, Lina e Charlotte voltaram à cena das publicações e exposições a partir dos anos 1990 e sua obra passou a ser estudada e pode ser parcialmente revelada, numa cena intelectual que mostra, pouco a pouco, que houve vários modernismos. 
Silvana Rubino

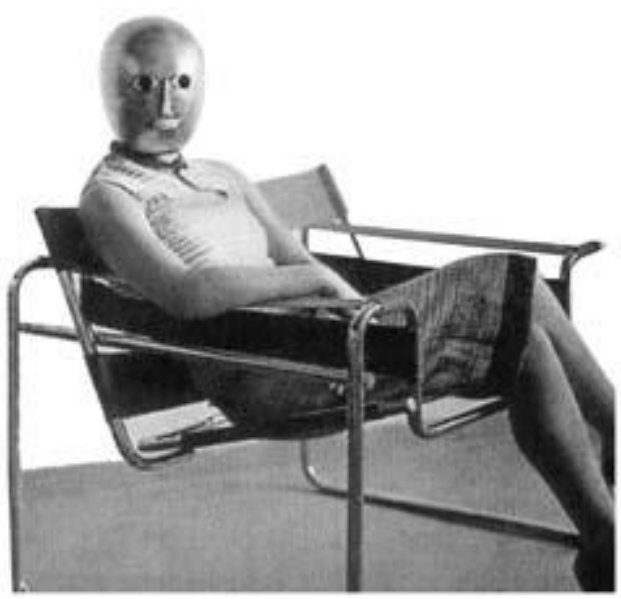

\section{Referências bibliográficas}

BARSAC, Jacques. Charlotte Perriand, un art d'habiter. Paris, Norma Éditions, 2005.

BuLLOCK, Nicholas. First the Kitchen - then the Facade. Journal of Design History, vol. 1, n 3/4, 1988.

CAMPEllo, Maria F. Lina Bo Bardi: As moradas da alma. Dissertação de Mestrado, Departamento de Arquitetura e Planejamento Urbano, EESC, Universidade de São Carlos, São Carlos-SP, 1996.

CHADWICK, Whitney. Living simutaneously. Sonia \& Robert Delaunay. In: CHADWICK, W. e CoURTIVRON, I. (eds) Significant others. Cretivity \& Intimate Partnership. New York, Thames \& Hudson, 1993, pp.3148.

ClARK, T.J. A pintura da vida moderna. Paris na arte de Manet e de seus seguidores. São Paulo, Companhia das Letras, 2004.

COHEN, Jean Pierre. Le Corbusier and the Paris Exhibition of 1937. The Temps Nouveaux Pavilion. Journal of the Society of Architectural Historians, vol. 56, $\mathrm{n}^{\circ}$ 1, 1997, pp. 42-63. 
Corpos, cadeiras, colares

COlOminA, Beatriz. The split wall: domestic voyeurism. In: COLOMINA, B. (ed) Sexuality and space. New York, Princeton Architectural Press, 1992, pp. 73-128.

COSTA MEYER, Esther. Simulated domesticities: Perriand before Le Corbusier. In: MCLEOD, Mary. (org.) Charlotte Perriand: an art of living. New York, Harry Abrams Inc. Publishers, 2003, pp. 22-35.

DROSTE, Magdalena. Bauhaus. Berlim, Benedikt Taschen, 1990.

FERRAZ, Marcelo. (org.) Lina Bo Bardi. São Paulo, Empresa das Artes/Instituto Lina Bo e P. M. Bardi, 1993.

KIRKHAM, Pat. Humanizing modernism: the crafts, 'functioning decoration' and the Eameses. Journal of Design History, vol 11, $\mathrm{n}^{\circ} 1$, Design History Society, 1998, pp.15-29.

LE CORBUSIER. Precisões sobre um estado presente da arquitetura e do urbanismo. São Paulo, Cosac \& Naify, 2004 [1930].

Loschiavo dos Santos, Maria C. Móvel moderno no Brasil. São Paulo, Studio Nobel/FAPESP/EDUSP, 1995.

MCLEOD, Mary. New designs for living: domestic equipment of Charlotte Perriand, Le Corbusier and Pierre Jeanneret, 1928-29. MCLEOD, Mary. (org) Charlotte Perriand: an art of living. New York, Harry Abrams Inc. Publishers, 2003, pp. 36-67.

PERRIAND, Charlotte. Une vie de création. Paris, Odile Jacob, 1998.

RuBINO, S. A escrita de uma arquiteta. RuBINO, S. e GRINOVER, M. (org.) Lina por escrito. Textos escolhidos de Lina Bob Bardi. São Paulo, Cosac \& Naify, 2009, pp19-40.

- Rotas da modernidade: trajetória, campo e história na atuação de Lina Bo Bardi. Tese de Doutorado, IFCH, UNICAMP, 2002.

RuEGG, Arthur. Charlotte Perriand Livre de Bord. Basel/Boston/Berlin, Birkhäuser publications for Architecture.

SILVERMAN, Debora L. Art nouveau in fin-de siècle France: politics, psychology and style. Berkeley, University of California Press, 1992. 